ISSN 1112-9867

http://www.jfas.info

\title{
USING WIND TURBINES IN HIGH-RISE BUILDINGS IN THE DEVELOPMENT OF SUSTAINABLE ARCHITECTURE (CASE STUDY: KISH ISLAND)
}

\author{
F. Asadpour**1, S. Khastoo ${ }^{2}$ and M. H. Rezaeian Fard ${ }^{3}$ \\ ${ }^{1}$ Master of Architecture, Lecturer of SAMA Technical and Vocational Center, Noor Branch, \\ Islamic Azad University, Noor, Iran \\ ${ }^{2}$ Master of Architecture, Noor Branch, Islamic Azad University, Noor, Iran \\ ${ }^{3}$ Master of Architecture, Mahmudabad Branch, Islamic Azad University, Mahmudabad, Iran
}

Published online: 15 May 2016

\begin{abstract}
The increasing consumption of fossil fuels as limited sources of energy and its destructive effect on the environment has drawn many people attention to the use of renewable energy and in the meantime, taking advantage of the renewable energy of wind to produce clean and low-cost energy is one of the most common options throughout the world, however, due to the growing concentration of population and economic activity in contemporary cities and for increasing high-rise buildings in order to answer the problem cause irreparable damage to the environment which in order to protect the God-given natural resources, reducing environmental pollution and reducing energy consumption, using wind turbines for wind energy and converting it into mechanical and electrical energy are objectives of sustainable development plays a major role in the housing sector. Since the shallow waters of the Persian Gulf and coasts of this region are great places for installing wind turbines, in this regard,
\end{abstract}

Author Correspondence, e-mail: asadpoor.faezeh@yahoo.com

doi: http://dx.doi.org/10.4314/jfas.v8i3s.235 
this study by studying documents and field studies to evaluate how the use of wind energy in high-rise buildings of these areas in order to maintain the environmental and energy efficiency leads to better planning for the construction of high-rise on Kish island in order to achieve the objectives of sustainable development.

Keywords: Renewable Energy, Wind Energy, Wind Turbine, High-Rise Buildings, Kish Island, Sustainable Architecture

\section{INTRODUCTION}

Strategy of high rise buildings and spatial development in height as population growth and increasing urbanization and the lack of suitable land for the building, in recent decades, become widespread. The formations of such buildings due to its characteristics, in addition to their positive effects are also faced with limitations and threats (Golabchi, 2011).

The issue of the integration of such buildings due to their limited level users as well; utilization and power consumption is both during construction and during operation. Therefore, it is essential that high-rise building design strategies to deal with this issue in order to save on the consumption of non-renewable resources with purpose of viability and sustainability for future generations that is the main goal of sustainable development. (Daneshpur et al, 2009). In this regard, the use of renewable sources to generate electricity is inevitable. In the meantime, due to the low price of electricity generated by wind power compared to other renewable sources, electricity generation from wind power has received so much attention (Howington, 1987). This is despite the fact that we have enough wind over the years in a city, wind energy is a good option for power generation at home (Hajian, 2015). The coastal waters in the world are the best areas to install wind turbines. In these areas the wind speed is higher than on land because of air friction with water is more than air friction with dry land (Gandomkar, 2010). The shallow waters of the Persian Gulf and the coast of this region a great place for installing wind turbines. In areas with constant and high-speed wind of 8 knots (4 meters per second) wind turbines can be used for a variety of uses (Badran, 2003).

The study of wind conditions at the synoptic stations during 1981 to 1985 showed that the 
country station in Zabol (Sistan) has the best conditions for the construction of wind farm (Kaviani, 1995). After Sistan region, the Persian Gulf and coastal waters of this region are very favorable conditions for installation of wind turbines (Gandomkar, 2006). And since Kish Island is located in southern Iran and the Persian Gulf coastal waters adjacent with Hormozgan province. According to the survey 3 hour wind in Kish Island station, an annual average wind speed in the island 8.6 knots (3.4 meters per second) and the maximum wind speed recorded at this station was 47 (23.5 meters per second) which was higher than the average and made the use of wind turbines in these areas is possible (Gandomkar, 2010).

The purpose of this study was to examine how the use of wind energy in made high-rise buildings of Persian Gulf coastal areas to maintain and energy efficient without environmental impact tried to sync to take advantage of this renewable energy as a priority in the construction of the region for sustainable development aims to have optimize energy consumption and minimize environmental pollution.

\section{THE CONCEPT OF SUSTAINABILITY}

\section{2-1 Sustainability in dictionary}

The word Sustain "' was used since 1290 in the English language and the Latin root is "Sub" and "tenere" means holding or storing and other forms of word meanings, "Sustain" existed for centuries but only in the past few decades that the term "sustainability" with its current meaning, i.e. it has been applied what can be sustained in the future (Dahghani, 2013).

Persian culture specific words in the dictionary and stability means resistance to the concept of sustainability from the root word "monitoring" means stability and strength and as an adjective it means: stable, lasting and resisting. Thus sustainability relies on maintaining stability. And it means what can be sustained in the future (Asadpour, 2013).

\section{2-2 Sustainable Development}

Looking for sustainable community concepts such as development protection that the planet can guarantee people welfare however, at this time his development would be threatened if resources would not be protected. Reviews ended to a report entitled (Common Future) in 1987. By the end of the Cold War, the ozone layer hole was discovered in 1085 and a year 
after the Chernobyl disaster, the report insisted on a main axis: most of the current development trends make many people poorer and cause more vulnerable and damage to the environment, so how this development can be effective in the next century the population is doubled. So we need a development path that makes human progress not only in a few locations for several years but for the distant future and it emerged that one of the most popular acceptable development: sustainable development is development that meets the needs of the current world without the ability of future generations to endanger satisfying their needs (Ghobadian, 2003).

\section{SUSTAINABLE ARCHITECTURE}

The application of sustainability concepts and sustainable development in architecture has created a new subject called sustainable architecture. The main ideas of sustainable architecture are the ability to change and have flexibility and potential energy (energy that is used to produce materials) (Soleimani, 2008). Sustainable architecture, as well as other categories of architecture, has its own principles and it consists of three stages: Save resources, designed to return to the life cycle, designed for human, they each have their own special strategy and identifying and studying these concepts, the architecture reaches to further understanding of the environment that should be designed (Davarinejad, 2009).

\section{PRINCIPLES OF SUSTAINABLE DESIGN}

Some buildings have features and properties that put them in the category of sustainable buildings. The principles that must be met to classify a building as a sustainable architecture, as follows:

The first principle, energy conservation: the building shall be so constructed that have a minimum need to fossil fuels.

The second principle, coordination with the climate: buildings should be designed to adapt with the climate and energy resources.

The third principle, reducing the use of new sources of materials: buildings should be designed in a way that reduce the use of new resources as much as possible and at the end of 
their useful life be used as a new source for the new building.

The fourth principle, to meet the needs of residents; in sustainable architecture to meet the spiritual and physical needs of the residents has great importance.

The fifth principle, coordination with the site: The site should be located in the ground gently and be compatible with the surrounding environment.

The sixth principle, holism: all principles of sustainable architecture are embodied in the entire process leading to the creation of a healthy environment (Asadpour, 2013).

\section{A SUSTAINABLE APPROACH IN HIGH-RISE BUILDINGS}

High-rise building in the world is a phenomenon which was started from the late 19th century and early 20th century, the first step in the production of skyscrapers in Chicago was taken from around 1880 to 1900 (Azizi, 1999). In the twentieth century, issues such as population growth, the need to accommodate more people in cities, the need to use most of the land in populated urban centers, the need to rebuild and modernize the urban areas, the demand for people to live or work in cities and the need to reduce the costs of horizontal expansion of cities were factors of making tall buildings as a necessity in large cities (Golabchi, 2001). Since normally such consume a large amount of resources for building both during construction and during operation and even when they reach the end of its life and destruction also losses a lot of energy, so essentially they are in conflict with sustainability goals. But given the high prevalence of necessity at the present time and future, it is necessary that designers involved in the construction, modification, seeking its negative effects on the environment on the one hand and on the other hand the people and its users. Therefore, in this study, the realization of sustainability objectives has been done on these high-rise buildings.

\section{RENEWABLE ENERGY AND WIND TURBINES}

Wind power like other renewable energy sources is scattered widely geographically and decentralized and yet is almost always available. The benefits of wind energy are as follows:

- No need to fuel turbines, which in turn reduces the amount of fossil fuel consumption.

- Wind energy is free. 
- The ability to meet part of the demand for electrical energy

- Wind-energy is cheaper than fossil fuels

- Less current cost of investment cost of wind energy in the long run

- Diversify the sources of energy and create a sustainable energy system

- No need to water

- Not causing environmental pollution compared to fossil fuels (Renewable Energy Organization of Iran, SUNA)

Wind power turbine consists of a tower on top of the engine. Generator, "Nossel," which is to say more scientific gearbox, main shaft and other electrical and required electronic components are located. Wind and air masses colliding with the wind turbines on the top of the tower and connected to the main shaft, the blades begin to move and transfer the power to the main axis, since the wind speed is not enough to rotate the main shaft at high speeds which is required for generator, the gearbox is used and turns low speed of rotation of the turbine blades to a higher speed. This speed depends on the type of generator and in many cases is about 50 times the speed of the turbine blades (Khalaji, Asadi and Safaei, 2001).

The turbine process is quite the contrary process of a fan. The fan electricity is converted to mechanical energy and spinning the blades. In wind turbines, the blades rotating kinetic energy of wind into mechanical energy and then into electricity, the wind hits the blades and rotate them. The main axis of rotation of the blades rotates. The shaft is connected to a power generator. The rotation of the generator generated AC power (SUNA).

\section{THE POTENTIAL OF WIND ENERGY IN IRAN}

Studying the wind potential energy for electricity production or other use is an important part of the of wind energy. Most countries in the world to use wind energy to produce role of wind energy potential at homogenous lines, these studies have less difficulties in the plain areas, in mountainous areas that are not exposed to atmospheric general streams. The local winds (Local) is more important. Given the circumstances and the extent of its topography and geographical scope Iran is considered in a second group which includes local winds and coastal areas. In this regard the north of Iran (Manjil, ROODBAR and North Qazvin) can be 
named. Based on measurements taken between the potential of 900-1500 watts per square meter is calculated for these areas. Persian Gulf coasts and coastal waters of this region are very favorable conditions for installation of wind turbines (Mostafaei, 2015). In these areas the wind speed is higher than on land because of air friction with water is less than air friction with dry land (Gandomkar, 2010). Because in areas with constant and high-speed wind of 8 knots (4 meters per second), wind turbines can be used for a variety of uses (Badran, 2003).

\section{STATISTICAL ANALYSIS OF WIND SPEED IN KISH ISLAND}

Kish Island is located in southern Iran and the Persian Gulf coastal waters adjacent with Hormozgan province. According to the survey station 3 hour wind in Kish Island; an annual average wind speed in the island is 8.6 knots (3.4 meters per second) and the maximum wind speed recorded in the station was 47 knots (23.5 meters per second) (Gandomkar, 2010).

In $45.7 \%$ of recorded times, wind speed is zero or less than 8 knots that is not appropriate to use wind energy but in $54.3 \%$ of recorded times, wind speed is more than 8 knots that is appropriate to use wind energy. In $40.3 \%$ of time wind speeds between 8 and 16 knots at $13 \%$ of time it is between 16 and 24 knots and at $1 \%$ of time it is more than 24 knots (figure 1) (Gandomkar, 2010).

Wind direction at a speed higher than 8 knots in this station has one main direction and a minor direction is opposite, about $47 \%$ of the wind direction the angle was between 270 to 310 degrees and in $18 \%$ wind direction was between 90 and 120 degrees. In fact, it can be stated that the fastest winds on the island has a main directions (west) and a lateral direction (east) (Figure 2 and 3), that in most time of the year is a stable wind direction for Kish Island Station. Due to the high speed and direction of winds are constant during the year as well as shallow beaches on the edge of the island, by constructing wind farms of offshore water around the island, to produce the needed electricity from wind energy for the island and use it in most time of the year and helped to preserve the environment and sustainable development in the island and the Persian Gulf region (Gandomkar, 2010). 


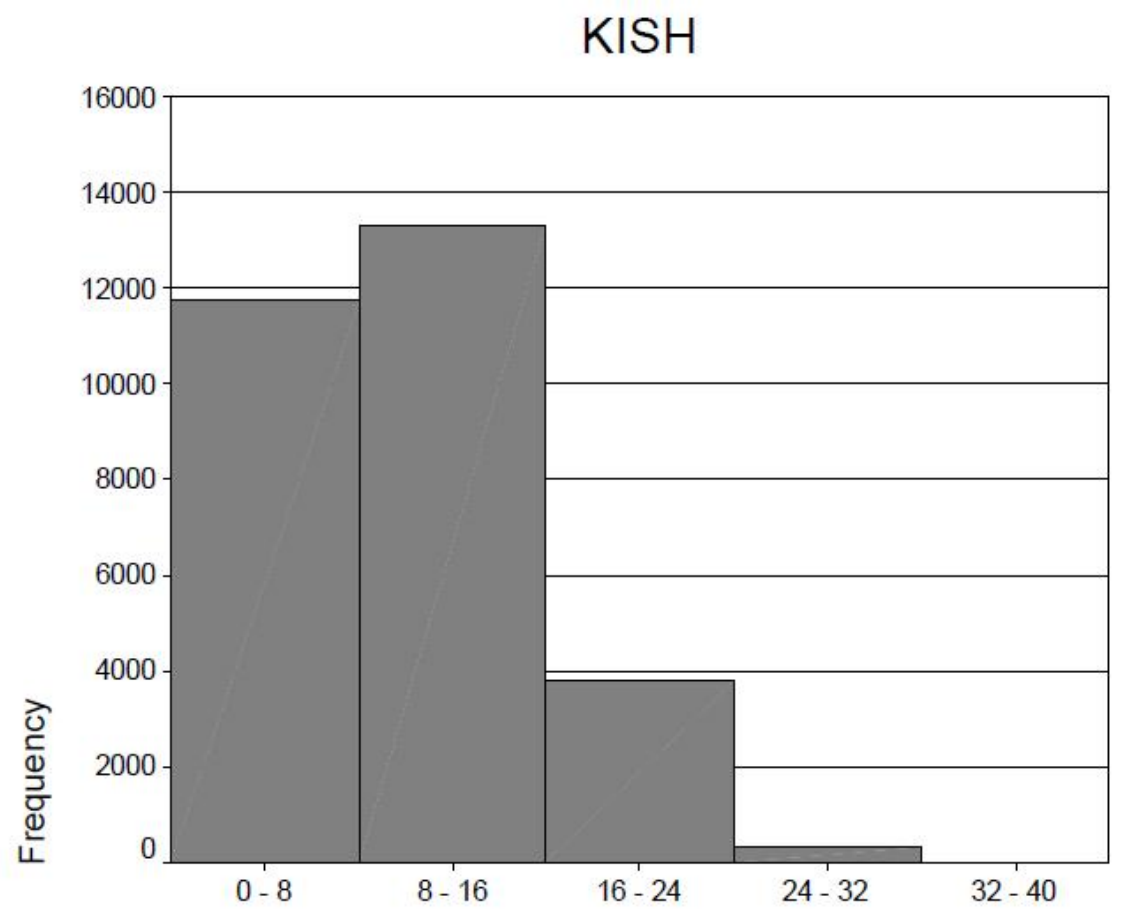

Fig.1.Histogram of wind speed at Kish Island station

$\mathrm{KISH}$

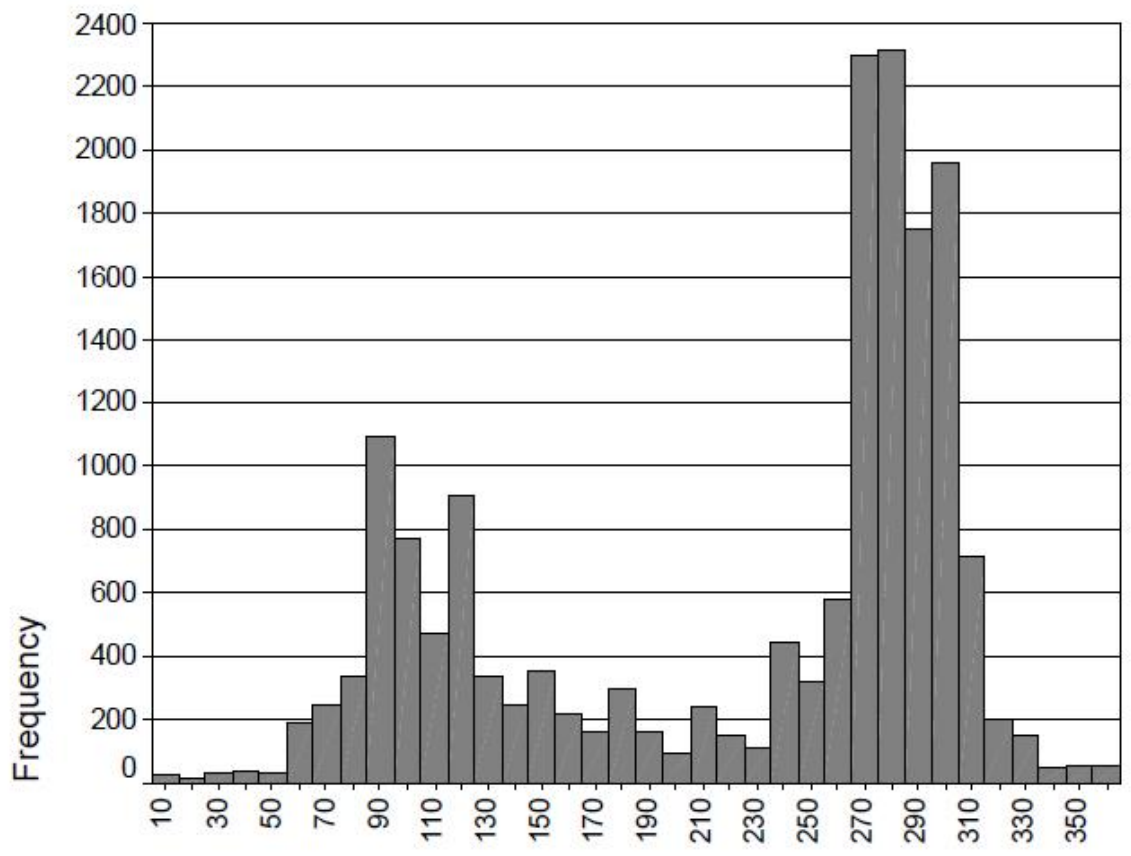

Fig.2. Histogram of wind direction at Kish Island station 


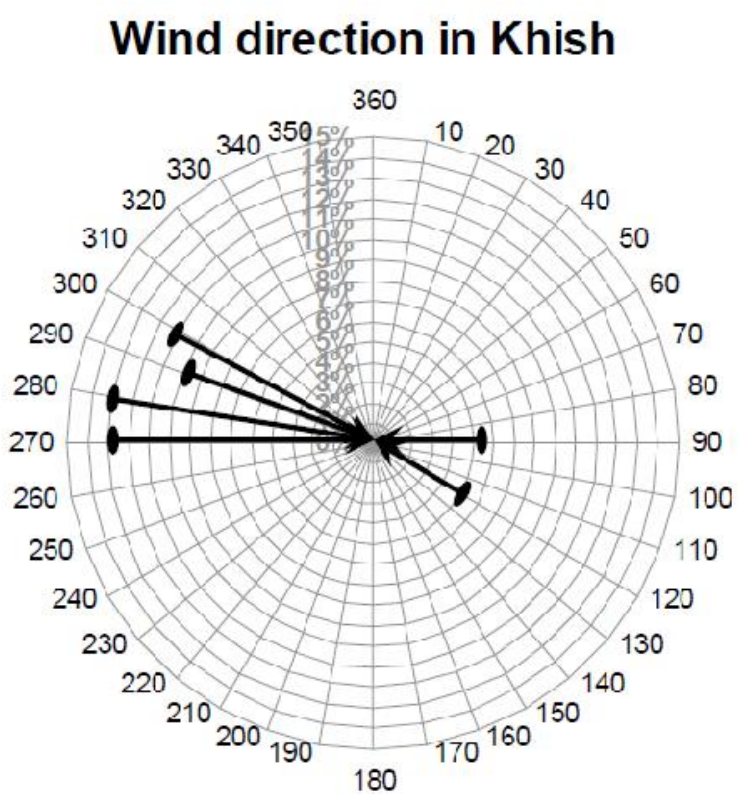

Fig.3. Main wind directions at Kish Island

\section{USING WIND TURBINES AT HIGH-RISE BUILDINGS IN THE PERSIAN GULF}

\section{9-1 Bahrain World Trade Center}

For the first time the use of wind power as a clean energy was at the World Trade Center in Bahrain in 2008. It was designed by using an eco-technological approach, including the twin towers were connected by three turbines in parallel and vertically (Figure 4) (Mostafaei, 2015). The three bridge towers connected together, wind turbines contain capacity of 225-kilowatt and total of $675 \mathrm{KW}$. Each of the turbines has 29 meters in diameter and is toward the north Persian Gulf that the prevailing wind direction is high (Figure 5). The sail-shaped building was designed for better flow of wind. Wind turbines are able to supply 11-15 percent of all power consumed about 1/1-1.3 gigawatt hours per year, respectively. This amount is equivalent to lighting of 300 homes. 3 turbines were been designed for the first time on April 8, 2008 and on average 50 percent of the daytime are working (http://www.khoobine.com). 


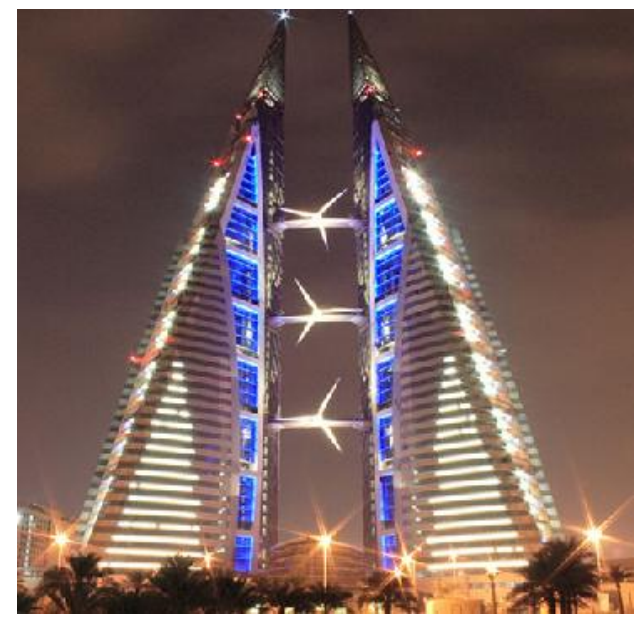

Fig.4. Bahrain World Trade Center

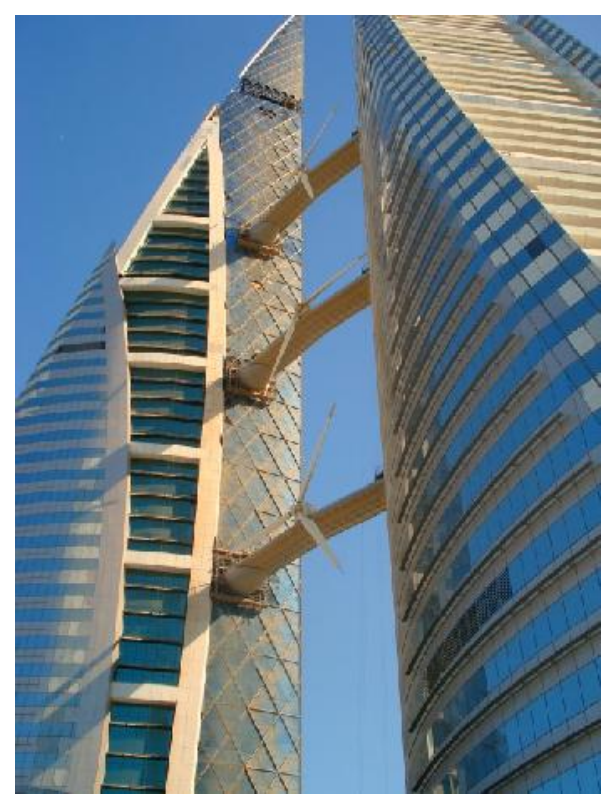

Fig.5. A view of locating three wind turbines between two tower buildings

\section{9-2 Dubai Dynamic Tower}

Dubai Dynamic Tower (As well as dynamic architecture building or tower, also known as the Da Vinci tower) Is a rotating skyscraper that is going to be built in Dubai, United Arabic Emirates. The building at 420 meters (1378 feet) high and 80 - floor was designed by an architect; David Fisher. Each class is able to slowly rotate 360 degrees around its center individually have at one point; the rotation speed can reach 6 meters per minute (Figure 6). (http://www.slideshare.net) 


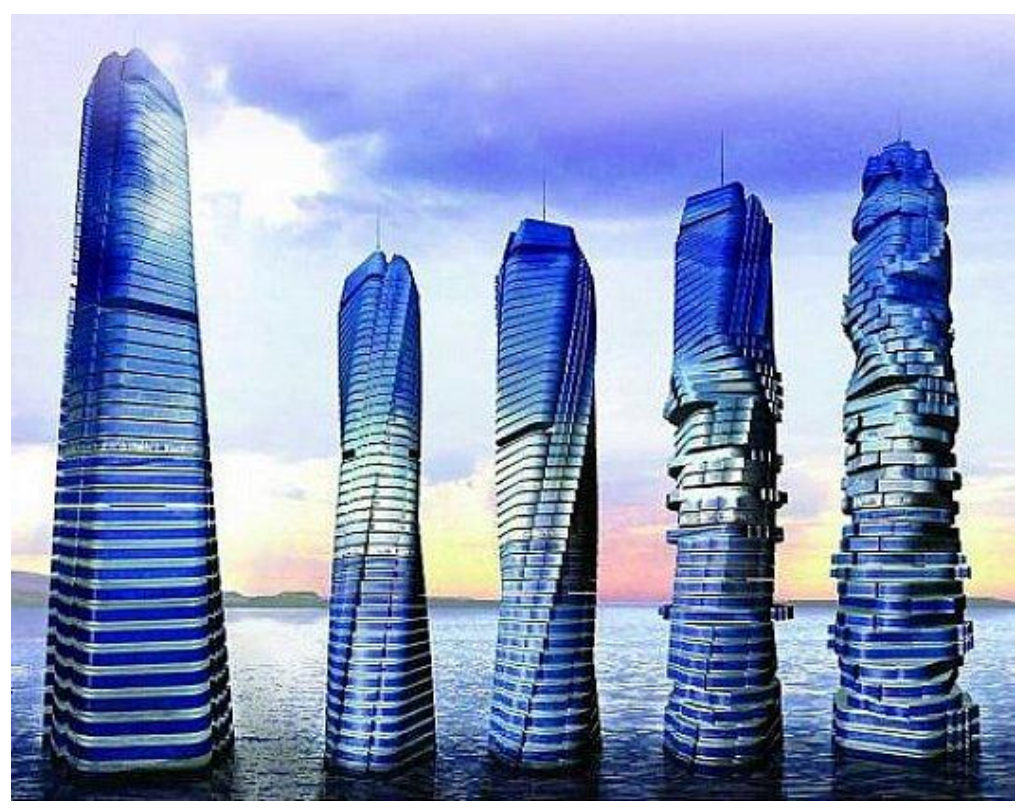

Fig.6. Different modes spinning floors in the tower

The building with changing form will be able to supply its electric power and solar panels and wind turbines by using wind power and sunlight, without causing any pollution will provide all the needed energy that will be worth the equivalent of 7 million $\$$. Each turbine can produce 0.3 megawatts of electricity (each vertical and normal wind turbine produces 1-1.5 MW). With regard to the four thousand hours annually in Dubai wind turbines used in the building can generate $1,200,000 \mathrm{kWh}$ of energy. Given that the average energy consumption per household is estimated to be 24 thousand kilowatt-hours per turbine can provide 50 families energy (Fig. 7 and 8) (http://www.slideshare.net).

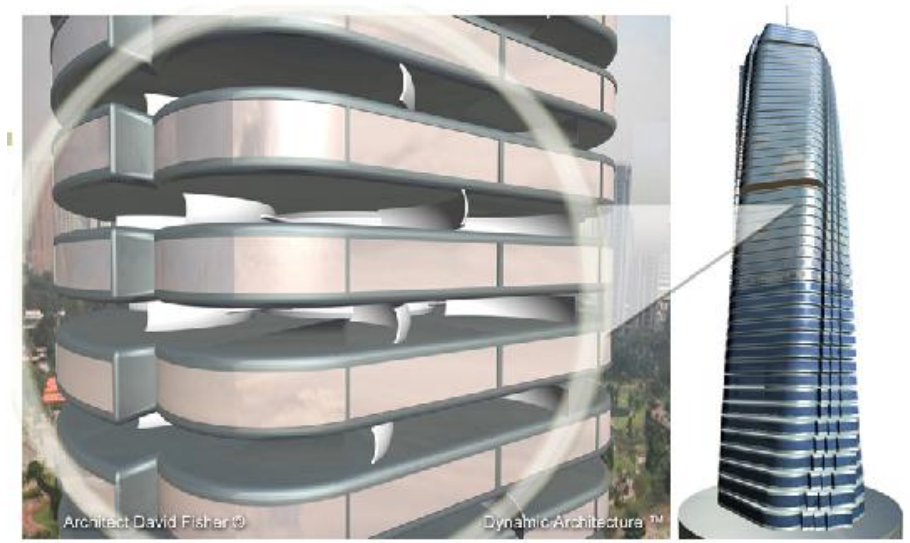

Fig.7. Placements of turbines in each floor 


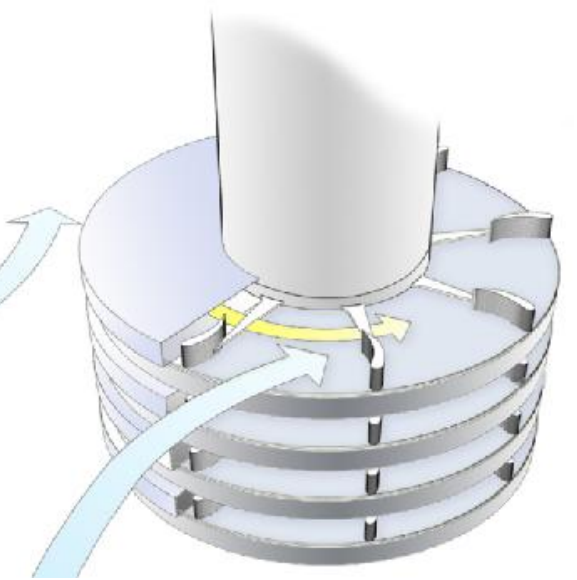

Fig.8. How to use turbines wind energy

\section{9-3 Clocks the sun tower- Dubai}

Dubai International Financial Centre is scheduled to start in the tower. Four thousand solar panels and three wind turbines of $225 \mathrm{~kW}$ in the southern part of the North it is embedded in this tower (Fig. 9 and 10). The tower's power is supplying from these two areas. (http://hi4tech.blogfa.com)

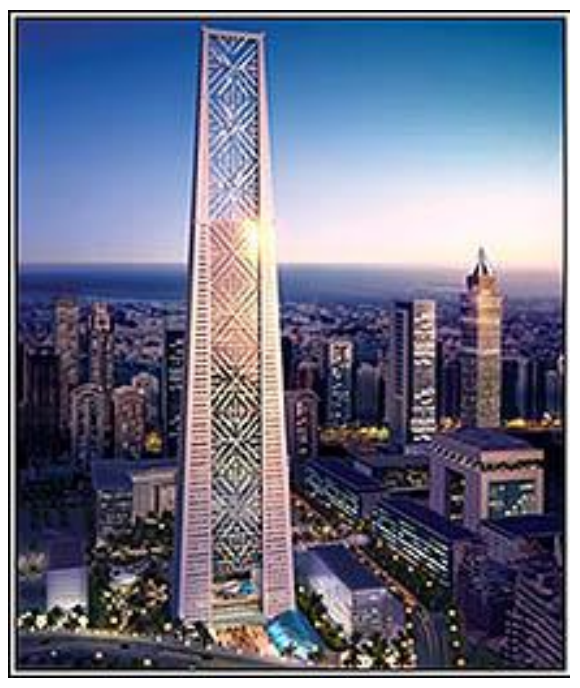

Fig.9. Overview of the Tower 


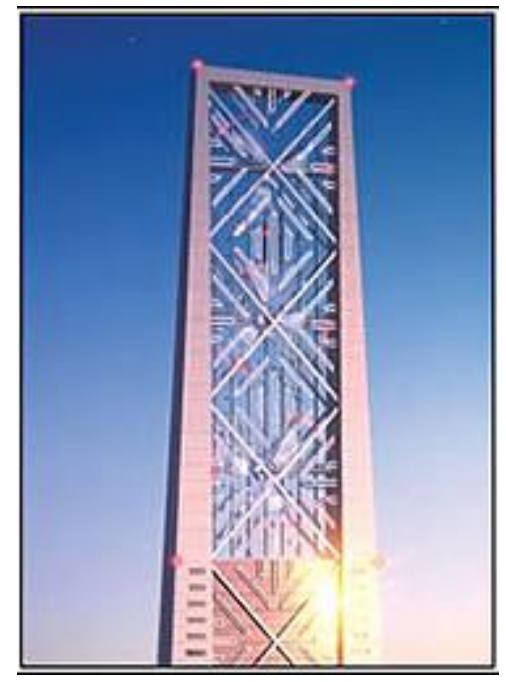

Fig.10. The location of the three turbines at the top of the tower

\section{9-4 Anara Tower in Dubai}

This beautiful tower was built in Dubai. The tower was designed by an English company called Atkins. The skyscraper has 125 floors and between each of its 27 floors, a park-like green space was designed and on top of the tower, in the central part of its turbine, a restaurant in the glass room and capsule-like with a great view was designed. It is likely that turbines located on top of the building are for supplying energy (Figure 11). Since the height of buildings is a lot, thus it is placed in air flow and by converting wind energy into electricity can meet the energy needs of the building day and night. If this happens, it will have higher rank among smart buildings (Fig, 12). (http://memari85.blogspot.nl)

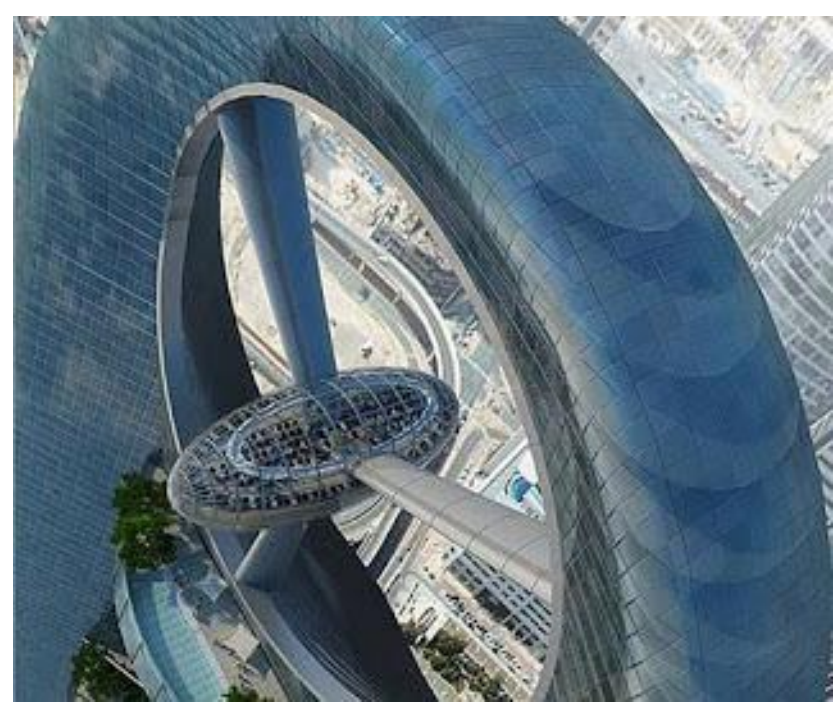

Fig.11. The location of turbine at the top of tower and the restaurant in it 


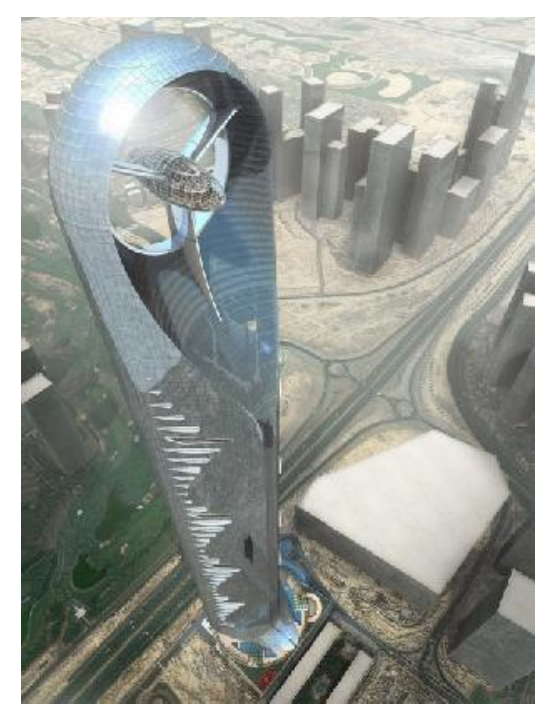

Fig.12. Overview of the Tower

\section{CONCLUSION}

Strategy of high rise buildings and spatial development in height as population growth and increasing urbanization and the lack of suitable land for the building, in recent decades, become widespread and with limited user-level integration, utilization and power consumption both during construction and during operation in this kind of buildings has taken place, as a result of the new energy and renewable wind energy to generate electricity is very rapidly growing but taking advantage of this energy must be appropriate to the weather conditions of the area to lead to massive investment. Therefore, in this study, by using meteorological data Kish Island in the Persian Gulf country's coastal areas has the ability to produce energy of wind power all year round in parts of the day (noon and evening) and also with review samples of high-rise buildings built in the Persian Gulf, the conclusion was by taking advantage of wind turbines in high-rise buildings due to the potential conversion area in the region, effective steps can be taken, for sustainable development and optimize energy consumption and minimize environmental pollution and in the overall view increases the quality of the urban environment. 


\section{REFERENCES}

- Asadpour, F et al (2013), The role of climatic factors in sustainable building design (Case Study: City of Light), National Congress of Architecture, Planning and Sustainable Development, Mashhad.

- Hajian, Ehsan, 2015, New method for the production of electricity from wind energy, JAME JAM newspaper

- Khalaji Asadi, Morteza and Safaei Batul, 2003, Check installed wind power plants in Iran of technical and economic point of view, Eighteenth International Conference on Electrical, p. 446.

- Daneshpour, Seyed Abdolhadi, et al, 2009, the role of environmental psychology in high-rise buildings with sustainable architecture approach, the identity of the city magazine, \# 5.

- Renewable Energy Organization of Iran, SUNA

- Dehghani Marjan and Haghpanah, Maryam, 2013, the role of environmental and climate in the design of sustainable architecture, sustainable architecture and urban development National Conference, Bukan, p. 2.

- Davarinejad, M, Masoud, M (2009) "Adapting to climate perspective," architecture magazine Urban Development, Tehran, No. 24, November 72, S483-494.

- Soleimani, Ali, (2008), "Land and sustainable architecture", architecture and culture magazine, p.16.

- Azizi, M., (1999), "Effects of physical-spatial tower making in Tehran". College of Fine Arts, Tehran University Press, 4 and 5, Page 35.

- Qobadian, V., (2003), the traditional buildings, the second edition of Tehran, Tehran, Page 57.

- Kaviani, MR (1995), wind turbines and assessment of wind energy potential in Iran, Geographical Research Quarterly, Issue 36

- Gandomkar, Amir, 2010, sustainable development and environmental protection of the island, using wind energy, Journal of the Persian Gulf. 
- Gandomkar, Amir, 2006, to investigate the synoptic wind energy in Sistan region, climate $\mathrm{PhD}$ Dissertations University of Isfahan.

- Golabchi, Mahmoud, 2001, the criteria for designing and building high-rise, College of Fine Arts, Tehran University Press, No. 9, p. 9.

- Mostafaei, Maryam and Mahdieh, 2015, The role of eco-technological solutions in the design of buildings with energy-saving approach, Proceedings of the National Conference of architectural and structural innovations in science, civil engineering, Shiraz.

- Howington, B. S., "Dynamic Thermal Line Rating Summary and Status of the State-of-the-Art Technology" IEEE Trans. On Power Delivery, Vol. 2, No. 3, pp. 851-858, 1987.

- Badran, o. (2003), Wind turbine utilization for water pumping in Jordan, Journal of wind, Engineering and Industrial Aerodynamics, 2003, 1203-1214.

- http://www.khoobine.com

- http://www.slideshare.net/swapnika15/dynamic-da-vincirotating-tower

- http://hi4tech.blogfa.com/post-14.aspx -

http://memari85.blogspot.nl/2009/02/blog-post_729.html

\section{How to cite this article:}

Asadpour F, Khastoo S, Rezaeian Fard M. H. Using wind turbines in high-rise buildings in the development of sustainable architecture (case study: Kish island). J. Fundam. Appl. Sci., 2016, 8(3S), 1069-1084. 